\title{
EDITORIAL
}

\section{The misguided attempt to replace psychopathological evaluation with DSM}

\author{
Cristina Lóyzaga Mendoza ${ }^{1}$
}

\begin{abstract}
1 Clínica de TOC y Trastornos del Espectro, Dirección de Servicios Clínicos, Instituto Nacional de Psiquiatría Ramón de la Fuente Muñiz.

Correspondence:

Cristina Lóyzaga Mendoza

Clínica de TOC y Trastornos del

Espectro, Dirección de Servicios

Clínicos, Instituto Nacional de Psiquiatría Ramón de la Fuente Muñiz.

Calz. México-Xochimilco 101, Col. San Lorenzo Huipulco, Del. Tlalpan, C.P. 14370, Ciudad de Méxi$\mathrm{co}$, México.

Phone: +52 (55) 4160-5254 Email: dra.cristinaloyzaga@gmail. com
\end{abstract}

doi.10.17711/SM.0185-3325.2017.017
The syllabus for training psychiatrists in the $21^{\text {st }}$ century has changed radically in recent decades. Although advances in neurosciences using various techniques to address the etiology and physiopathology of mental disorders have provided objective information to locate them in their corresponding place in medical pathology, certain essential elements of medicine have been lost, such as a broad clinical interview and a detailed semiology, both of which are essential to arriving at a correct diagnosis and providing an accurate therapeutic approach. On the subject of loss, there is an increasing disincorporation from study programs in the specialty from disciplines such as philosophy, sociology, and anthropology, which nourishes psychiatry and give it a crucial multidisciplinary quality to understand the person suffering a mental disorder.

This assessment of the gains and losses in psychiatry suggests there has been a decline in the training of specialists in this area, which has obviously had an impact on the understanding of problems affecting humans' emotions, thoughts, and behavior. A special element for the analysis of these lost aspects is psychopathology, a key tool in psychiatry, which consists of the "systematic study of abnormal cognitive, affective, and behavioral experience" (Jaspers, 1996). Using this tool requires teaching theoretical aspects, and developing this skill requires empathy, clinical acuity and a detailed complete observation of the information patients provide in their speech and behavior. Psychopathology is the fundamental instrument used by clinicians to catch the patient's subjective experience in formulating narrative and diagnostic hypotheses (Capponi, 1988; Sims, 1995).

A look at the origins of the Diagnostic and Statistic Manual of Mental Disorders (DSM), shows that its predecessor appeared in 1952, with an extra-clinical origin, when the US Army requested that the forerunner of the American Psychiatric Association (2013) produce a "Practical Nosology" to evaluate the psychological symptoms observed in the trenches during the war (Requena, 2012). DSM-II, published in 1968, reflects a psychoanalytic vision of mental disorders, with all its limitations for the understanding of etiology and the provision of a therapeutic approach. In 1987, DSM-III was published, with the operative definition of diagnostic criteria (Requena, 2012). However, for many disorders, the essential and defining characteristics required to make a diagnosis were not considered.

The proposal to create DSM-5, initially supported by the US National Institute of Mental Health, suggested designing criteria that would not only have defining clinical characteristics, but also other levels of information such as elements of genetics, brain imaging, and cognitive science. However, the later version failed to meet these objectives, leading the institution to disassociate itself from the new manual (Insel, 2013).

There is clearly a need for a diagnostic classification of mental disorders (Belloch, 2008) as an initial approach to the phenomenon under study, to establish a common language among clinicians by providing terms for communication. It could also be a useful basis for formulating diagnostic, therapeutic, and prognostic hypotheses. However, one of the main criticisms leveled at DSM is the validity and reliability of the same, which have persisted in each updated version (Vanhuele, 2014). Another feature that has elicited criticism is the type of categorical classification, which makes it difficult to evaluate dimensional aspects of clinical phenomena, and does not appear to take into account the fact 
that in clinical practice, the limits between them are often fuzzy (Alarcón, 1991).

Berrios's criticisms of DSM essentially focus on the fact that not all problems addressed by psychiatry originate in a specific part of the brain. He highlights the importance of the close relationship between biology and culture in the development of mental disorders, and considers that each society has its own approach to illnesses. Thus the DSM classification system is perfectly suited to the North American society that created it, but does not apply to other cultures (Berrios, 2012).

In Nombrar y comprender, Pérez-Rincón states: "Designating and classifying has never been an innocent or a random event $[\ldots]$ the changes described not only reflect the progress of science, but have always been embedded in the social structure." To which I would add that underlying the social processes are the economic transformations guiding the objectives of scientific research, which do not always have a scientific purpose (Pérez-Rincón, 1993).

An interesting but not always easily visible fact is that behind the use of DSM as a substitute for classical texts, or the use of semi-structured interviews associated with the criteria of this manual, is the pragmatism involved in evaluating patients, and the attempts to cut the costs of psychiatric care. The work of John Bernal, a pioneer in the study of the relationship between science and society (Bernal, 1997), suggests that beyond these paradigm shifts we must reflect on the role of science at a specific historical moment, whose research question it seeks to answer and how this impacts the everyday practice of the knowledge obtained. Likewise, the sociologist Hilary Rose has written on how the prevailing economic model guides scientific research and teaching, in order to perpetuate the values and knowledge of capitalism (Rose, 1976). Taking these aspects into account, it is feasible to think that the quicker forms of evaluation and the standardization of pathological processes also form part of the globalization policies imposed, in which tools such as the DSM can be useful for these purposes, as the goal of those who create them and as an illusion for rather naive clinicians who do not question its implications.

In my view, the most reprehensible feature of this manual is the excessive, inappropriate use made of it, particularly in clinical and academic spheres, in a misguided attempt to replace the teaching and practice of accurate clinical interviews, semiology, and psychopathology, and abandon classical readings. In this regard, in clinical training environments for psychiatry residents, excessive importance is placed on reading and memorizing DSM criteria at the expense of learning about and practicing clinical interviews, mental exams, semiology, and producing full, descriptive clinical notes. In many cases, the latter activities have been replaced by a brief note to comply with the administrative requirement of the case. Even medical history that need as broad and descriptive an approach as possible, including a full mental examination, are terse and frequently merely check the boxes for characteristics such as suffers/does not suffer from delirium, suffers/does not suffer from hallucinations.

This indifference, whether conscious or not, towards the teaching and use of the tools of psychopathology and semiology, among others, wastes the opportunity to evaluate the patient in a comprehensive, accurate, and interdisciplinary manner. We lose valuable evaluations for arriving at a diagnosis and providing treatment and improvement, as well as opportunities for clinical and basic research.

In this context, which is overwhelming because of its importance and vast scope, how can we escape these difficulties? One possibility is to reexamine the seminal writings on psychopathology. The classic authors are always an endless source of knowledge, and a starting point for new questions and different approaches and conceptions. The language of psychiatry is still being written, and there are many terms that require a clearer definition and research into how they occur in various clinical scenarios. Terms such as insight and diffuse clinical states, such as the coexistence of apparently divergent symptoms such as those observed in the schizo-obsessive phenomenon and pathological doubt, are just some examples that open up opportunities for research on semiological and psychopathological aspects. We should obviously take up these elements in everyday clinical practice in order to have a better understanding of the people sitting opposite us and telling us their experiencial problems in order to help them improve their lives.

\section{REFERENCES}

Alarcón, R.D. (1991). Hacia el DSM-IV: historia reciente, estado actual y opciones futuras. Acta Psiquiátrica y psicológica de América Latina, 37(2): 105-122.

American Psychiatric Association. (2013). Diagnostic and statistical manual of mental disorders (DSM-5). American Psychiatric Publishing.

Belloch A., Sandin B., \& Ramos F. (2008). Manual de Psicopatología. Madrid: McGraw Hill, 94-95.

Bernal, J.D. (1997). La Ciencia en nuestro tiempo. México: Nueva imagen. 432- 439.

Berrios, G. (2012, October 17). Cada país genera su locura. [Interview in Diario La $\mathrm{Voz}]$, Argentina.

Capponi, R. (1988). Psicopatología y semiología psiquiátrica. Santiago, Chile: Editorial Universitaria, 22-27.

Insel, T. (2013, April 29). Transforming Diagnosis. [Post in the site of the National Institute of Menthal Health]. Retrieved from https://www.nimh.nih.gov/about/ directors/thomas-insel/blog/2013/transforming-diagnosis.shtml

Jaspers, K. (1996). Psicopatología general (pp. 8-9). Mexico: Fondo de Cultura Económica.

Pérez-Rincón, H. (1993). Nombrar y comprender. Revista del residente de psiquiatría, 4(1), 6-9.

Requena E., \& Jarne A. (2012). Sistemas de clasificación y diagnóstico. In A. Jarne \& A. Talarn (Eds.), Manual de psicopatología clínica (pp. 65-102). Barcelona: Herder Editorial.

Rose H., \& Rose E. (1976). Political economy of the science: Ideology in/of the natural Science: Macmillan Publisher.

Sims, A. (1995). Symptoms in the mind. An introduction to descriptive psychopathology (pp. 1-4). London: Saunders Company Ltd.

Vanheule, S. (2014). Diagnosis and DSM: A Critical Review (pp. 35-53). UK: Palgrave Macmillan Publisher. 